\title{
ESTUDOS DE GÊNERO EM INTERFACE COM SIGNOS E MÍDIA: APROXIMAÇÕES MUITO TÍMIDAS
}

\author{
Gender studies interfacing signs and media: \\ very timid approaches
}

\section{Estudios de género en interfaz con signos y medios: aproximaciones muy tímidas}

\author{
Cláudia Lago \\ Universidade de São Paulo, São Paulo, Brasil \\ Professora do Departamento de Comunicações e Artes da Escola de Comunicações e Artes da \\ Universidade de São Paulo (CCA-ECA/USP) e do Programa de Pós-Graduação em Ciências da \\ Comunicação da mesma instituição. Coordenadora do Grupo de Pesquisa Alteridade, Subjetividades, \\ Estudos de Gênero e Performance nas Comunicações e Artes (AlterGen). Doutora em Ciências da \\ Comunicação pela ECA/USP e mestre em Antropologia Social pela Universidade Federal de Santa \\ Catarina. Graduada em Jornalismo pela Faculdade Cásper Líbero. \\ E-mail: claudia.lago07@usp.br
}

\section{Elisa Canjani}

Universidade de São Paulo, São Paulo, Brasil

Mestranda do Programa de Pós-Graduação em Ciências da Comunicação (PPGCOM-ECA/USP) da Universidade de São Paulo. Integra o grupo de pesquisa Alteridade, Subjetividades, Estudos de Gênero e Performance nas Comunicações e Artes. Graduanda em Licenciatura em Educomunicação pela ECA-USP. Arquiteta e Urbanista pela FAU-USP.

E-mail: elisa.canjani@usp.br

\section{Isabella Bergo}

Universidade de São Paulo, São Paulo, Brasil

Mestranda do Programa de Pós-Graduação em Ciências da Comunicação (PPGCOM-ECA/USP) da Universidade de São Paulo. Integra o grupo de pesquisa Alteridade, Subjetividades, Estudos de Gênero e Performance nas Comunicações e Artes. Graduada em Ciências da Comunicação com Habilitação em Cinema pela Fundação Armando Álvares Penteado (FAAP).

E-mail: isabella.bergo@usp.br

RESUMO Investigando a base de dados das revistas Comunicação, Mídia e Consumo e Signos do Consumo, esse artigo busca perceber como pesquisas que trabalham questões de gênero na interface Comunicação e Consumo se apropriam e dialogam com o campo de Estudos de Gênero a partir de sua complexidade e interdisciplinaridade. Os resultados apontam para uma excessiva timidez, tanto em termos da quantidade de materiais que fazem uso dessa relação, quanto em termos da aproximação efetiva do arcabouço temático e teórico conceitual fornecido pelo campo.

PALAVRAS-CHAVE Comunicação, Consumo, Estudos de gênero, Comunicação, Mídia e consumo, Signos do consumo. 
ABSTRACT Researching the database of the journals Comunicação, Mídia e Consumo and Signos do Consumo, this article seeks to understand how research that works on gender issues in the Communication and Consumption interface appropriates and dialogues with the field of gender studies from its complexity and interdisciplinarity. The results point to an excessive shyness, both in terms of number of studies that make use of this relationship, and in terms of the effective approximation of the thematic and conceptual framework provided by the field.

KEYWORDS Consumption, Gender studies, Comunicação, Mídia e consumo, Signos do consumo.

RESUMEN A partir de búsquedas en la base de datos de las revistas Comunicação, Mídia e Consumo y Signos do Consumo, este artículo busca comprender cómo la investigación que trabaja sobre temas de género en la interfaz Comunicación y Consumo se apropia y dialoga con el campo de los estudios de género, pensados desde su complejidad e interdisciplinariedad. Los resultados apuntan a una excesiva timidez tanto en la cantidad de materiales que hacen uso de esta relación como en la aproximación efectiva del marco temático y el marco conceptual que brinda el campo.

PALABRAS-CLAVE Comunicación, Consumo, Estudios de género, Comunicação, Mídia e Consumo, Signos do Consumo

\section{INTRODUÇÃO}

As questões de gênero ganham visibilidade social na contemporaneidade, especialmente quando aparecem entrelaçadas a outros marcadores que transformam a diferença em desigualdade social. Esta proeminência pode se ver refletida em produtos culturais midiáticos, como em campanhas publicitárias ou práticas de consumo e, por conseguinte, também no campo de pesquisa da Publicidade e do Consumo, defendido por Trindade (2019) como um subcampo com lógicas próprias e tendências específicas.

Partindo do pressuposto da centralidade do campo da Publicidade e do Consumo para a constituição das subjetividades, interessa-nos pensar como as pesquisas ligadas a este campo se relacionam com outro espaço interdisciplinar e complexo, o campo de Estudos de Gênero que, por sua vez, tem papel central na reflexão sobre a construção do masculino e do feminino, das sexualidades, da exclusão de tudo que não se encaixe na binaridade heteronormativa e dos atravessamentos de outros marcadores sociais como raça/etnia, classe, idade, região, etc. nestas construções.

A aproximação entre os dois campos é mais do que necessária. Scott (1995), em texto já clássico, advoga que gênero ${ }^{1}$ tem que ser colocado para se pensar o conjunto da produção científica no campo da História, com o qual a autora dialoga. Apesar de muito utilizado para tão somente conceituar gênero, a linha condutora do texto de Scott é indicar que este não deve ser apenas um elemento descritivo das pesquisas, mas tem que se constituir enquanto uma categoria de análise que perpasse todos os objetos em vez de constituir apenas um eixo temático, apartado da discussão de outros temas. Da mesma forma, advogamos este uso para nosso campo. Não perceber que a construção de gênero/sexualidade/raça-etnia/classe etc. perpassa o universo da Comunicação é não iluminar suficientemente nossos objetos e, em certa medida, é também reforçar as construções naturalizadas atreladas a estas tecnologias, considerando-se a centralidade destes no sentido de

1. A autora também aponta para a junção de gênero com classe e raça, exemplificando outros dois atravessamentos necessários às pesquisas. 
constituição/reforço ou circulação de lugares, estereótipos e sua operação enquanto potentes tecnologias de gênero (LAURETIS, 1994).

Há uma relação ainda tímida (MARTINEZ; LAGO; LAGO, 2016) quando observamos a Comunicação (e/ou seus subcampos) em aproximação com os Estudos de Gênero, apesar de trabalhos recentes (TOMAZETTI, 2019) apontarem para seu crescimento nos últimos anos, tanto em termos qualitativos das pesquisas quanto em ampliação das temáticas. Observamos pouca aderência, com o uso de bibliografias limitadas e recorrência de autores(as) canônicos, mas menor uso de autores(as) com pesquisas recentes, menções a conceitos-chave sem explicitação e correlação teórica mais aprofundada.

Em relação específica ao universo da Recepção e Consumo Midiático, Tomazetti e Coruja (2017) apontam para a presença incipiente da relação das pesquisas com os Estudos de Gênero. Das 191 pesquisas de Recepção e Consumo Midiático analisadas (teses e dissertações produzidas entre 2010 e 2015), apenas quinze ${ }^{2}$ se detiveram às relações de gênero, dessas, a maioria (doze) é relacionada aos estudos do feminino/feminismos e as outras três são relativas às sexualidades/estudos queer, além disso, há também um trabalho voltado às questões das masculinidades ${ }^{3}$.

A necessidade de aproximar os campos da Recepção e Consumo Midiático motivou a realização desta pesquisa. A perspectiva foi circunscrever este mapeamento a produções que dialogassem direta e intencionalmente com o universo do consumo e, por isso, nos detivemos a artigos publicados recentemente a duas revistas de nosso campo que objetivam discutir a interface Comunicação e Consumo: Signos do Consumo, ligada ao Departamento de Relações Públicas Propaganda e Turismo da Escola de Comunicações e Artes da Universidade de São Paulo (CRP-ECA/USP) e Comunicação, Mídia e Consumo, publicação quadrimestral do Programa de Pós-Graduação em Comunicação e Práticas de Consumo da Escola Superior de Propaganda e Marketing São Paulo (ESPM-SP).

Apesar da diferença entre as revistas referidas (tempo de existência, índice Qualis, número de edições por ano etc.), acreditamos que ambas são referência para aqueles/as que se propõem a atuar na interface Comunicação e Consumo. Sob esse ponto de vista, as revistas são bases de dados que nos permitem um olhar mais aprofundado, mesmo que não exaustivo.

\section{OLHANDO O CORPUS E TRAÇANDO ANÁLISES}

Baseado em técnicas de coleta da análise de conteúdo (Bardin, 2011) complementadas com análises interpretativas dos textos, em um primeiro momento a palavra-chave "gênero" foi usada para selecionar artigos publicados entre janeiro de 2015 e julho de 2020 nas revistas Signos do Consumo e Comunicação, Mídia e Consumo. A pesquisa com a palavra-chave foi feita em 22 e 23 de setembro de 2020 e resultou em 40 e 17 artigos, respectivamente. Em uma segunda triagem, os artigos que traziam a palavra gênero em contextos que não o de relações de gênero, como gênero literário e gênero musical foram descartados, resultando em 16 artigos na Signos e 9 artigos na Mídia e Consumo (como

2. A soma das pesquisas totaliza dezesseis e não quinze, pois um dos textos é alocado em mais de uma das categorias propostas pelo texto.

3. Os(as) autores/as utilizam outros descritivos para as pesquisas, mas aproximamos as categorias do que usaremos em nosso trabalho. 
são comumente chamadas as revistas). A terceira triagem consistiu em retirar os artigos que foram captados na busca por terem a palavra gênero mesmo no contexto de relação, mas apenas como palavra-menção, sem tratar do tema. Com esta nova triagem foram retirados 5 artigos da Signos, mas se mantiveram os 9 artigos da Mídia e Consumo, com isso, o corpus inicialmente analisado se compõe de 20 artigos, conforme tabelas abaixo.

Tabela 1. Comunicação, Mídia e Consumo.

\begin{tabular}{|c|c|c|c|}
\hline Ano & Título & Autores/as & Instituições/Links para os textos \\
\hline 2015 & $\begin{array}{l}\text { Circulação de Ideias e } \\
\text { Apropriações Culturais } \\
\text { na Diáspora Negra }\end{array}$ & $\begin{array}{l}\text { Maria Angélica } \\
\text { Zubaran, Juliana } \\
\text { Ribeiro de Vargas }\end{array}$ & $\begin{array}{l}\text { Universidade Luterana do Brasil } \\
\text { http://revistacmc.espm.br/index. } \\
\text { php/revistacmc/article/view/1054 }\end{array}$ \\
\hline 2017 & $\begin{array}{l}\text { "What's Going On é o } \\
\text { Sgt. Pepper's da soul } \\
\text { music": autonomia, } \\
\text { cânone e valor numa } \\
\text { lista de maiores álbuns } \\
\text { da música }\end{array}$ & $\begin{array}{l}\text { Adriana da Rosa } \\
\text { Amaral, Thiago } \\
\text { Soares, Camila } \\
\text { Franco Monteiro }\end{array}$ & $\begin{array}{l}\text { Unisinos; UFPE; University of } \\
\text { Huddersfield } \\
\text { http://revistacmc.espm.br/index. } \\
\text { php/revistacmc/article/view/1272 }\end{array}$ \\
\hline 2017 & $\begin{array}{l}\text { O ativismo digital de } \\
\text { Lorelay Fox: estética e } \\
\text { performance de gênero }\end{array}$ & $\begin{array}{l}\text { Josefina de Fatima } \\
\text { Tranquilin Silva }\end{array}$ & $\begin{array}{l}\text { Uniso } \\
\text { http://revistacmc.espm.br/index. } \\
\text { php/revistacmc/article/view/1316 }\end{array}$ \\
\hline 2017 & $\begin{array}{l}\text { Formas de } \\
\text { representação feminina } \\
\text { nos teen chick lits: um } \\
\text { estudo em torno d'O } \\
\text { diário da princesa. } \\
\end{array}$ & $\begin{array}{l}\text { Alleid Ribeiro } \\
\text { Machado }\end{array}$ & $\begin{array}{l}\text { Universidade Presbiteriana } \\
\text { Mackenzie. } \\
\text { http://revistacmc.espm.br/ } \\
\text { index.php/revistacmc/article/ } \\
\text { view/0000-0001-9359-532X }\end{array}$ \\
\hline 2018 & $\begin{array}{l}\text { E elxs viverão felizes } \\
\text { para sempre? (In) } \\
\text { visibilidades de } \\
\text { personagens } L G B T \text { em } \\
\text { producões da Disney } \\
\text { como força propulsora } \\
\text { de ciberacontecimentos }\end{array}$ & $\begin{array}{l}\text { Felipe Viero } \\
\text { Kolinski Machado, } \\
\text { Christian Gonzatti, } \\
\text { Francielle Esmitiz }\end{array}$ & $\begin{array}{l}\text { UFMG, UFOP, Unisinos, Unisinos } \\
\text { http://revistacmc.espm.br/index. } \\
\text { php/revistacmc/article/view/1535 }\end{array}$ \\
\hline 2019 & $\begin{array}{l}\text { Telenovelas brasileiras, } \\
\text { mulheres da classe } \\
\text { dominante e a moderna } \\
\text { tradição de gênero }\end{array}$ & $\begin{array}{l}\text { Veneza Mayora } \\
\text { Ronsini, Hellen } \\
\text { Panitz Barbiero, } \\
\text { Otávio Chagas } \\
\text { Rosa, Marina } \\
\text { Machiavelli } \\
\end{array}$ & $\begin{array}{l}\text { UFSM; UFSM; UFSM; UFSM; } \\
\text { http://revistacmc.espm.br/index. } \\
\text { php/revistacmc/article/view/1880 }\end{array}$ \\
\hline 2019 & $\begin{array}{l}\text { Strike a pose! } \\
\text { A mediação do } \\
\text { videoclipe "Vogue" } \\
\text { em performances do } \\
\text { Carnaval carioca }\end{array}$ & $\begin{array}{l}\text { Simone Pereira de } \\
\text { Sá, Rodolfo Viana } \\
\text { de Paulo }\end{array}$ & $\begin{array}{l}\text { UFF; UFF. } \\
\text { http://revistacmc.espm.br/index. } \\
\text { php/revistacmc/article/view/1901 }\end{array}$ \\
\hline 2019 & $\begin{array}{l}\text { O discurso publicitário } \\
\text { sobre a incontinência } \\
\text { urinária: "doença } \\
\text { silenciosa" }\end{array}$ & $\begin{array}{l}\text { Daniela Zeni } \\
\text { Dreher1 } \\
\text { Cassia Engres } \\
\text { Mocelin2 Maria } \\
\text { Simone Vione } \\
\text { Schwengber3 } \\
\end{array}$ & $\begin{array}{l}\text { Unijuí; PUC-RS; Unijuí } \\
\text { http://revistacmc.espm.br/index. } \\
\text { php/revistacmc/article/view/1963 }\end{array}$ \\
\hline 2020 & $\begin{array}{l}\text { Sobre infância, saúde } \\
\text { e gênero: discursos } \\
\text { biomédicos na mídia } \\
\text { impressa de } 1990 \\
\end{array}$ & $\begin{array}{l}\text { Heloísa Derkoski } \\
\text { Dalla Nora, Eliane } \\
\text { Cadoná }\end{array}$ & $\begin{array}{l}\text { URI } \\
\text { http://revistacmc.espm.br/index. } \\
\text { php/revistacmc/article/view/2132 }\end{array}$ \\
\hline
\end{tabular}

Fonte: Elaborado pelas autoras, 2020. 
Tabela 2. Signos do Consumo

\begin{tabular}{|c|c|c|c|}
\hline Ano & Título do artigo & Autores/as & $\begin{array}{l}\text { Instituições/Links para } \\
\text { textos }\end{array}$ \\
\hline 2016 & $\begin{array}{l}\text { Mujeres en Círculo: análise do } \\
\text { ativismo virtual gerado por } \\
\text { uma comunidade feminista } \\
\text { no Facebook }\end{array}$ & Deborah Rodriguez & $\begin{array}{l}\text { UFF } \\
\text { http://www.revistas.usp.br/ } \\
\text { signosdoconsumo/article/ } \\
\text { view/114878 }\end{array}$ \\
\hline 2016 & $\begin{array}{l}\text { Do consumo de marcação } \\
\text { à marcação do consumo: } \\
\text { \#riachuelo e a moda } \\
\text { midiatizada }\end{array}$ & Lívia Silva de Souza & $\begin{array}{l}\text { USP } \\
\text { http://www.revistas.usp.br/ } \\
\text { signosdoconsumo/article/ } \\
\text { view/114487 }\end{array}$ \\
\hline 2016 & $\begin{array}{l}\text { Os memes e sua apropriação } \\
\text { pelo marketing digital: a } \\
\text { experiência da rede brasileira } \\
\text { de fast-food Giraffas }\end{array}$ & $\begin{array}{l}\text { Antonio Hélio } \\
\text { Junqueira }\end{array}$ & $\begin{array}{l}\text { UAM } \\
\text { http://www.revistas.usp.br/ } \\
\text { signosdoconsumo/article/ } \\
\text { view/114905 }\end{array}$ \\
\hline 2017 & $\begin{array}{l}\text { Algumas coisas não são } \\
\text { muito verdadeiras”: consumo } \\
\text { midiático e recepção da } \\
\text { publicidade televisiva na } \\
\text { infância }\end{array}$ & $\begin{array}{l}\text { Fárida M. Rabuske } \\
\text { Kuntz e Elisa } \\
\text { Reinhardt Piedras }\end{array}$ & $\begin{array}{l}\text { UFSM; UFRGS } \\
\text { http://www.revistas.usp.br/ } \\
\text { signosdoconsumo/article/ } \\
\text { view/115000 }\end{array}$ \\
\hline 2017 & $\begin{array}{l}\text { "Dona dessa beleza”: } \\
\text { empoderamento feminino, } \\
\text { corpos diferentes e inclusão no } \\
\text { discurso publicitário da Avon }\end{array}$ & $\begin{array}{l}\text { Leonardo } \\
\text { Mozdzenski, Keliny } \\
\text { Cláudia da Silva e } \\
\text { Liliana Barros Tavares }\end{array}$ & $\begin{array}{l}\text { UFPE; UFPE; COM } \\
\text { Acessibilidade } \\
\text { Comunicacional } \\
\text { http://www.revistas.usp.br/ } \\
\text { signosdoconsumo/article/ } \\
\text { view/124151 }\end{array}$ \\
\hline 2017 & $\begin{array}{l}\text { Cultura corporativa: } \\
\text { determinante ou limitante } \\
\text { estratégico para o Branding }\end{array}$ & $\begin{array}{l}\text { Martha Gabriel e } \\
\text { Clotilde Perez }\end{array}$ & $\begin{array}{l}\text { PUC-SP; USP } \\
\text { http://www.revistas.usp.br/ } \\
\text { signosdoconsumo/article/ } \\
\text { view/141002 }\end{array}$ \\
\hline 2017 & $\begin{array}{l}\text { Fronteiras da religião: a } \\
\text { comunicação no Instagram } \\
\text { entre o Papa Francisco e as } \\
\text { mulheres }\end{array}$ & $\begin{array}{l}\text { Cláudio de } \\
\text { Musacchio e Jociane } \\
\text { Marchesan Oling) }\end{array}$ & $\begin{array}{l}\text { Portal EAD Brasil; PUC-RS } \\
\text { http://www.revistas.usp.br/ } \\
\text { signosdoconsumo/article/ } \\
\text { view/126834 }\end{array}$ \\
\hline 2018 & $\begin{array}{l}\text { Procedimentos essenciais } \\
\text { do processo de colonização } \\
\text { das práticas cotidianas de } \\
\text { consumo pelo lugar de poder } \\
\text { da produção }\end{array}$ & $\begin{array}{l}\text { Isaac Matheus Santos } \\
\text { Batista, Marcelo } \\
\text { Machado Martins e } \\
\text { Raquel de Aragão } \\
\text { Uchôa Fernandes }\end{array}$ & $\begin{array}{l}\text { UFRPE; UFPE; UFRPE } \\
\text { http://www.revistas.usp.br/ } \\
\text { signosdoconsumo/article/ } \\
\text { view/141231 }\end{array}$ \\
\hline 2019 & $\begin{array}{l}\text { Fulla a boneca muçulmana. A } \\
\text { formação da personalidade } \\
\text { de meninas islâmicas através } \\
\text { do ato de brincar }\end{array}$ & $\begin{array}{l}\text { Carolina Boari } \\
\text { Caraciola }\end{array}$ & $\begin{array}{l}\text { USP } \\
\text { http://www.revistas.usp.br/ } \\
\text { signosdoconsumo/article/ } \\
\text { view/150464 }\end{array}$ \\
\hline 2019 & $\begin{array}{l}\text { Diversidade, gênero } \\
\text { e consumo estudos } \\
\text { contemporâneos }\end{array}$ & Wilton Garcia & $\begin{array}{l}\text { Uniso } \\
\text { http://www.revistas.usp.br/ } \\
\text { signosdoconsumo/article/ } \\
\text { view/150757 }\end{array}$ \\
\hline 2019 & $\begin{array}{l}\text { A apropriação do social pela } \\
\text { publicidade Skol Reposter e } \\
\text { suas ideologias de consumo }\end{array}$ & Ana Paula Bragaglia & $\begin{array}{l}\text { UFF } \\
\text { http://www.revistas.usp.br/ } \\
\text { signosdoconsumo/article/ } \\
\text { view/146106 }\end{array}$ \\
\hline
\end{tabular}

Fonte: Elaborado pelas autoras, 2020. 
A primeira avaliação que podemos fazer sobre os textos que compõem o corpus de análise, e que salta aos olhos, é a timidez com a qual aparecem no subcampo do consumo (TRINDADE, 2019), já que no período foram publicados 229 artigos pelas revistas e nossa mostra inicial ser de apenas 20 .

Observamos que a maioria (12 de 20) foi escrita de forma colaborativa por mais de um(a) autor(a), muitas vezes com mais de dois(as). Com isso, apesar de serem 20 textos, temos 39 autores(as) envolvidos, a maioria expressiva (28), mulheres ${ }^{4}$. A maior parte dos textos tem autores(as) ligados(as) a instituições sediadas no Sudeste (10) e Sul (6); um texto tem autores(as) de instituições do Sul e do Sudeste, outro tem autores de instituições do Sul, do Nordeste e de um país estrangeiro; apenas dois textos são de autores(as) vinculados a instituições apenas do Nordeste.

Em termos de ano de publicação, o corpus é composto por um artigo de 2015 e outro de 2020, ambos na Mídia e Consumo; a Signos possui três em 2016 e a Mídia e Consumo nenhum. Nos anos 2017, 2018 e 2019 há uma semelhança em termos de publicações entre as revistas: em 2017 foram publicados 3 artigos pela Mídia e Consumo) e 4 pela Signos, em 2018, foram publicados um em cada uma das revistas e, em 2019, três em cada. O espaço temporal indica uma distribuição constante no período, com um declínio em 2018 que só pode ser interpretado se cotejado com avaliações em outras bases de dados.

Passamos então a nos ater a pensar o corpus em relação às temáticas, e, principalmente, aderência ao campo de Estudos de Gênero. Verificamos para a aderência, em uma primeira mirada, quais artigos mencionam a palavra gênero e/ou palavras que remetem ao campo de estudo (como "performance" e "feminismo", por exemplo) nos metadados (como título, resumo e/ou palavra-chave), já que esta menção é indicativa (ou deveria ser) da centralidade da temática na pesquisa. Percebemos que oito dos nove artigos da Mídia e Consumo fazem alusão ao campo nos metadados. A exceção é $O$ discurso publicitário sobre a incontinência urinária: doença silenciosa que, no entanto, remete à lógica dos estudos sobre mulheres. Neste caso, o texto, apesar de não usar gênero nos metadados, insere e apropria-se de enquadramentos e temáticas concernentes, como a problematização da representação da mulher cuidadora junto ao mercado de consumo por meio da propaganda analisada.

Na Signos do Consumo, sete textos têm palavras do campo de Estudos de Gênero nos metadados e um traz um termo no título: Fronteiras da Religião: a comunicação no Instagram entre o Papa Francisco e as mulheres, a ele retornaremos logo em seguida. Os três restantes, Do consumo de marcação à marcação do consumo, Os memes e sua apropriação pelo marketing digital e Cultura corporativa, não fazem alusão a termos do campo nos metadados. Do consumo de marcação à marcação do consumo: \#riachuelo e a moda midiatizada aponta a demarcação dos papéis de gênero na moda, no entanto sem aprofundar ou problematizar esta discussão.

Ao olharmos mais atentamente para estes textos, percebemos que eles apenas tangenciam timidamente perspectivas atinentes aos estudos de gênero. Ainda mais distante é o texto Fronteiras da religião: a comunicação no Instagram entre o Papa Francisco e as mulheres. O título leva a crer que o texto apresentará uma discussão sobre a comunicação específica do Papa Francisco (via Instagram), com um universal "mulheres”, mas, na verdade, detém-se à discussão da comunicação do Papa com seus fiéis.

4. Ainda que essa distinção muitas vezes perca o sentido se pensarmos nas críticas ressoantes e atuais contra o binarismo de gênero. 
As mulheres entram na discussão apenas por serem a ampla maioria dos fiéis que comentam as postagens - mas esse fato nem sequer é apontado como merecedor de algum aprofundamento. Aspecto semelhante se dá com texto que alude ao campo nos metadados, mas não o explora: "What's Going On é o Sgt. Pepper's da soul music”: autonomia, cânone e valor numa lista de maiores álbuns da música, publicado na Mídia e Consumo e que pensa a construção de cânones valorativos ligados a padrões de gosto evocados por homens brancos héteros e de camadas médias, perspectiva aderente, mas não explorada, apenas referida ${ }^{5}$.

Quando olhamos mais atentamente aos trabalhos que pretendem pensar sobre questões relativas ao campo de Estudos de Gênero, podemos verificar algumas temáticas. Como já indicado anteriormente, o campo é extremamente amplo e interdisciplinar e isso se reflete no universo das temáticas apresentadas pelos artigos, que passaram a ser categorizados, desta vez sem preocupação com a separação por revistas. Partindo desta complexidade, buscou-se verificar não apenas as temáticas em si, a aderência e apropriação das discussões sobre os estudos do campo de gênero, mas também se há uma perspectiva interseccional, ou seja, que pensa as questões relativas a entrelaçamentos com outros marcadores, como de raça e classe (LAGO; KAZAN; THAMANI, 2018).

Uma primeira categorização divide os artigos conforme a relação mais intensa que mantêm com aspectos específicos dos Estudos de Gênero. Com esta perspectiva, e trabalhando 15 artigos (foram retirados os já mencionados anteriormente, que mantêm apenas relações esparsas com o campo), foi encontrada a grande maioria, nove, relacionada à discussão da constituição do feminino e/ou do feminismo, três que interrogam questões relacionadas ao campo LGBTQIA+ e três que olham para a infância e a constituição de gênero. Na tabela abaixo indicamos estas temáticas e subdivisões possíveis.

Tabela 3.

\begin{tabular}{|c|c|c|c|}
\hline Ano & Título & $\begin{array}{c}\text { Temática } \\
\text { geral }\end{array}$ & $\begin{array}{c}\text { Temáticas } \\
\text { Secundárias }\end{array}$ \\
\hline 2015 & $\begin{array}{l}\text { Circulação de Ideias e Apropriações Culturais na } \\
\text { Diáspora Negra }\end{array}$ & $\begin{array}{l}\text { Feminino/ } \\
\text { ismos }\end{array}$ & $\begin{array}{l}\text { Negritude/ } \\
\text { Interseccionalidade } \\
\text { com raça }\end{array}$ \\
\hline 2016 & $\begin{array}{l}\text { Mujeres en Círculo: análise do ativismo virtual } \\
\text { gerado por uma comunidade feminista no } \\
\text { facebook }\end{array}$ & $\begin{array}{l}\text { Feminino/ } \\
\text { ismos }\end{array}$ & $\begin{array}{l}\text { Empoderamento/ } \\
\text { redes }\end{array}$ \\
\hline 2017 & $\begin{array}{l}\text { O ativismo digital de Lorelay Fox: estética e } \\
\text { performance de gênero }\end{array}$ & LGBTQIA+ & Visibilidades/redes \\
\hline 2017 & $\begin{array}{l}\text { Formas de representação feminina nos teen } \\
\text { chick lits: um estudo em torno d'O diário da } \\
\text { princesa. }\end{array}$ & $\begin{array}{l}\text { Feminino/ } \\
\text { ismos }\end{array}$ & $\begin{array}{l}\text { Empoderamento/ } \\
\text { cooptação }\end{array}$ \\
\hline 2017 & $\begin{array}{l}\text { Algumas coisas não são muito verdadeiras": } \\
\text { consumo midiático e recepção da publicidade } \\
\text { televisiva na infância }\end{array}$ & Infância & Lugares de gênero \\
\hline 2017 & $\begin{array}{l}\text { "Dona dessa beleza": empoderamento feminino, } \\
\text { corpos diferentes e inclusão no discurso } \\
\text { publicitário da Avon }\end{array}$ & $\begin{array}{l}\text { Feminino/ } \\
\text { ismos }\end{array}$ & $\begin{array}{l}\text { Empoderamento/ } \\
\text { Diferença }\end{array}$ \\
\hline
\end{tabular}

5. Em função desta relação rasante com o campo de estudos de gênero, estes artigos foram descartados no aprofundamento da discussão que faremos a seguir. 
Tabela 3. Continuação.

\begin{tabular}{|c|c|c|c|}
\hline Ano & Título & $\begin{array}{c}\text { Temática } \\
\text { geral }\end{array}$ & $\begin{array}{c}\text { Temáticas } \\
\text { Secundárias }\end{array}$ \\
\hline 2018 & $\begin{array}{l}\text { E elxs viverão felizes para sempre? (In) } \\
\text { visibilidades de personagens } L G B T \text { em } \\
\text { produções da Disney como força propulsora de } \\
\text { ciberacontecimentos }\end{array}$ & LGBTQIA+ & Visibilidades \\
\hline 2018 & $\begin{array}{l}\text { Procedimentos essenciais do processo de } \\
\text { colonização das práticas cotidianas de consumo } \\
\text { pelo lugar de poder da produção }\end{array}$ & $\begin{array}{l}\text { Feminino/ } \\
\text { ismos }\end{array}$ & $\begin{array}{l}\text { Cooptação/ } \\
\text { Interseccionalidade } \\
\text { com marcador de } \\
\text { classe }\end{array}$ \\
\hline 2019 & $\begin{array}{l}\text { Telenovelas brasileiras, mulheres da classe } \\
\text { dominante e a moderna tradição de gênero }\end{array}$ & $\begin{array}{l}\text { Feminino/ } \\
\text { ismos }\end{array}$ & $\begin{array}{l}\text { Interseccionalidade } \\
\text { com marcador de } \\
\text { classe }\end{array}$ \\
\hline 2019 & $\begin{array}{l}\text { Strike a pose! A mediação do videoclipe } \\
\text { "Vogue" em performances do Carnaval carioca }\end{array}$ & LGBTQIA+ & Visibilidades \\
\hline 2019 & $\begin{array}{l}\text { Fulla a boneca muçulmana. A formação da } \\
\text { personalidade de meninas islâmicas através do } \\
\text { ato de brincar }\end{array}$ & Infância & $\begin{array}{l}\text { Lugares de gênero } \\
\text { (sem contestação) }\end{array}$ \\
\hline 2019 & $\begin{array}{l}\text { Diversidade, gênero e consumo estudos } \\
\text { contemporâneos }\end{array}$ & $\begin{array}{l}\text { Feminino/ } \\
\text { ismos }\end{array}$ & $\begin{array}{l}\text { Empoderamento/ } \\
\text { Diversidade/ } \\
\text { Ensaístico }\end{array}$ \\
\hline 2019 & $\begin{array}{l}\text { A apropriação do social pela publicidade Skol } \\
\text { Reposter e suas ideologias de consumo }\end{array}$ & $\begin{array}{l}\text { Feminino/ } \\
\text { ismos }\end{array}$ & Cooptação \\
\hline 2019 & $\begin{array}{l}\text { O discurso publicitário sobre a incontinência } \\
\text { urinária: "doença silenciosa" }\end{array}$ & $\begin{array}{l}\text { Feminino/ } \\
\text { ismos }\end{array}$ & $\begin{array}{l}\text { Interseccionalidade } \\
\text { com marcador } \\
\text { idade }\end{array}$ \\
\hline 2020 & $\begin{array}{l}\text { Sobre infância, saúde e gênero: discursos } \\
\text { biomédicos na mídia impressa de } 1990\end{array}$ & Infância & Lugares de gênero \\
\hline
\end{tabular}

Fonte: Elaborado pelas autoras, 2020.

Se pensarmos nos artigos que se relacionam à problematização das representações/construção do feminino e/ou feminismos, apenas um tem como ponto de partida um olhar para a interseccionalidade de raça, o Circulação de Ideias e Apropriações Culturais na Diáspora Negra, ainda que esta discussão apareça en passant em outros artigos ${ }^{6}$. No texto referido, as autoras apontam como a imprensa negra - no caso o jornal O Exemplo, de Porto Alegre - se apropria de textos de outros veículos da imprensa sobre a campanha do monumento à Mãe Preta, na década de 1920, para criar novos significados. Sua conclusão é de que o jornal foi capaz de adaptar as narrativas hegemônicas, apontando críticas aos preconceitos étnico-raciais e afirmando as contribuições da população negra para o país, mantendo, porém, essencializações de gênero sobre uma Mãe Negra carinhosa e compassiva que colabora para o "mito" da democracia racial.

Uma intersecção com classe aparece em Procedimentos essenciais do processo de colonização das práticas cotidianas de consumo pelo lugar de poder da produção, texto no qual é detalhado que, ao longo dos anos o universo da moda e da alta costura foi engessado por uma forte

6. Strike a pose! A mediação do videoclipe "Vogue" em performances do Carnaval carioca; "Dona dessa beleza": empoderamento feminino, corpos diferentes e inclusão no discurso publicitário da Avon; 
barreira de classe e de gênero, o que se alterou após a década de 60 com os chamados baby boomers. Em Telenovelas brasileiras, mulheres da classe dominante e a moderna tradição de gênero se discute como as telenovelas se imbricam com a constituição de uma representação para a mulher de camadas altas. Por fim, a interseccionalidade, gênero e outros marcadores aparecem também em $O$ discurso publicitário sobre a incontinência urinária: "doença silenciosa" que aponta para a construção de gênero relacionada ao aspecto geracional.

Alguns textos, como Mujeres en Círculo: análise do ativismo virtual gerado por uma comunidade feminista no Facebook falam especificamente sobre empoderamento, o que também é o caso de "Dona dessa beleza": empoderamento feminino, corpos diferentes e inclusão no discurso publicitário da Avon, que fala de empoderamento de corpos desviantes dos padrões normativos em relação à campanha publicitária analisada.

Há também textos que falam de como práticas culturais contra hegemônicas, ou o próprio empoderamento, podem ser cooptados pelos sistemas midiáticos. É o caso de Formas de representação feminina nos teen chick lits: um estudo em torno d'O diário da princesa, texto no qual a autora olha para a apropriação das pautas feministas pelo mercado de consumo, especificamente o mercado editorial, enquanto perpetua estereótipos de gênero. Outro caso é o de $A$ apropriação do social pela publicidade Skol Reposter, texto no qual é afirmado que a marca opera um apagamento de seu passado sexista e se apropria dos discursos dos movimentos sociais feministas para se legitimar. Por fim, o artigo Diversidade, gênero e consumo estudos contemporâneos articula uma reflexão sobre diversidade, gênero e consumo a partir da percepção de estratégias no campo da comunicação atual, apresentando a questão da performatividade de gênero como uma possibilidade de reverter a falta de espaço das mulheres, apontando que a constituição de lugares de fala, visibilidade e empoderamento são importantes para se ocupar novos lugares e romper com a hegemonia dominante do gênero masculino.

Se pensarmos nos textos que trabalham temáticas relacionadas ao universo LGBTQIA+, veremos que os três gravitam em torno da questão das visibilidades e a atrelam a produtos da cultura pop (vídeos, universo Disney, videoclipes e performances no carnaval). O artigo Strike a pose! A mediação do videoclipe "Vogue" em performances do Carnaval carioca exemplifica essa vertente ao perguntar sobre a possibilidade de um carnaval com performances divergentes: "haveria espaço nas escolas de samba para uma forma de sambar 'mais gay'? Ou o 'bom desfile' (...) implica em não dar visibilidade a dançarinos e passistas 'que dão pinta', ou seja, que revelam, através de uma forma de dançar peculiar, a sua identidade de gênero?” (SÁ; PAULO, 2019, p. 389)

Em E elxs viverão felizes para sempre? (In)visibilidades de personagens LGBT em produções da Disney como força propulsora de ciberacontecimentos, os autores apontam que, embora as produções da Disney não rompam com a lógica heteronormativa e binária e, ainda que estejam a serviço da lógica mercadológica, abrem possibilidades para a construção de novos sentidos, interpretações, negociações e a ressignificação de experiências. Já $O$ ativismo digital de Lorelay Fox: estética e performance de gênero discute a estética e a performance da personagem ativista digital de gênero Lorelay Fox - criada por Danilo Dabague. É analisada no artigo a produção de sentidos em diálogo com o público em seu canal no YouTube apontando o fazer político e a transformação cultural na contemporaneidade, época em que as mediações tecnológicas se tornam estruturais. Interessante observar que 
estes dois artigos são extremamente aderentes ao campo de estudos de gênero, apropriando-se de autores(as) e abordagens bastante pertinentes a este universo.

Os artigos que gravitam em torno da infância apontam, em vários suportes (análise de jornais e publicidade) e de formas mais ou menos intensa, como se dá e percebe a construção de lugares de gênero desde a infância, seja em pesquisas que interrogam a recepção da publicidade, no ato de brincar ou nos discursos médicos sobre a infância. Em Algumas coisas não são muito verdadeiras": consumo midiático e recepção da publicidade televisiva na infância é apontado como mesmo crianças pequenas já fazem seleções com base em lugares tradicionais de gênero, sendo esta, na verdade, a única aproximação com o campo de estudos. Em Sobre infância, saúde e gênero: discursos biomédicos na mídia impressa de 1990, é apontada a construção destes lugares, atribuindo às mães a responsabilidade principal pelos cuidados, decorrência do "fator biológico/instintivo", num viés biologizante. Mais interessante é o caso de Fulla a boneca muçulmana. A formação da personalidade de meninas islâmicas através do ato de brincar que aborda a construção da marca da boneca mulçumana Fulla, inicialmente comparada (enquanto produto) à Barbie ocidental. O mais interessante do texto é a completa ausência de qualquer tom crítico à construção dos estereótipos de gênero, concentrando-se na defesa da marca como propagadora dos ideais de conformação do feminino que o texto padroniza como "mulçumanos".

\section{PARA CONCLUIR: RECORRÊNCIAS E UM CONSELHO NÃO SOLICITADO}

Após a leitura dos textos que constituíram o corpus de análise, pudemos perceber que se repetem situações já indicadas por outros mapeamentos, como o de Tomazetti e Coruja (2017), que indica a centralidade das pesquisas no eixo Sul-Sudeste e a timidez em comparação com o total do universo verificado.

Há a predominância de estudos que se organizam na esfera do feminino/feminismo, categoria que elencamos para indicar trabalhos que pensam a situação das mulheres, a partir das construções do gênero, olhando tanto para reforços como contraposições a estas construções. Empoderamento, aqui é palavra-chave de vários textos e fio condutor de outros, percebido em relação a sua cooptação pelas estratégias de mercado, especialmente. Gênero, portanto, ainda aparece fortemente ligado à mulher e ao feminino, e dentro desse universo, à mulher branca dos extratos mais altos da sociedade, atrelando valores estéticos, desejos de consumo e significado de "empoderamento feminino" específicos. A discussão, mesmo que crítica, olha insistentemente para um certo tipo de mulher, supostamente para "a mulher que consome" e isso pode levar a uma essencialização e apagamento das interseccionalidades.

Olhando para as obras que abordam gênero ou feminismo, as referências bibliográficas trazem maciçamente autoras brancas e, apesar de por vezes presente, a necessária junção dos olhares aos atravessamentos com outros marcadores sociais (raça/etnia, classe etc.), não perpassa a maioria dos textos, sendo explorada de forma variável em termos de aprofundamento em alguns. Isto denota um começo de amadurecimento da percepção da amplitude do olhar necessária quando refletimos sobre a desconstrução e desvelamento do naturalizado socialmente o que deve ser o objetivo último das pesquisas (LAGO, 2015). 
O universo LGBTQIA+ também é objeto de reflexão, ancorado na discussão da visibilidade e sua aproximação com objetos de consumo midiático e, importante observar, são textos que, em sua maioria, dialogam mais detidamente com o campo de Estudos de Gênero, com uma apropriação mais declarada das teorias circulantes naquele espaço. Interessante também apontar a presença de estudos que olham para a infância, observando-se que um aceita sem crítica (até defende) a constituição de gênero para meninas através do objeto de consumo. Por outro lado, é importante apontar a ausência de estudos que observam a constituição das masculinidades, cada vez mais recorrentes em outros ambientes que se apropriam dos estudos de gênero, apesar do termo aparecer em artigos em forma de bibliografia ou citação ${ }^{7}$.

Em termos de aderência, independente da qualidade ou propósito das pesquisas, percebemos uma timidez excessiva na relação ao campo de Estudos de Gênero. Apesar de trabalhos se apropriarem e realmente fazerem uso do arcabouço teórico daquele campo, vários pouco ampliam ou utilizam o amplo arsenal bibliográfico disponível, detendo-se geralmente a autores(as) mais "clássicos" e largamente utilizados. Em que pese a nosso trabalho não ter se detido em uma análise bibliométrica específica, não haveria espaço, é importante ressaltar essa percepção a partir da observação das referências bibliográficas dos artigos. Esta observação, aliada aos textos que fomos descartando pelo caminho por apenas darem um rasante no campo de estudos de gênero, nos incentiva a dar um conselho final, não solicitado.

Entendemos que vários dos textos analisados que não se propuseram a falar sobre gênero partiram de outros lugares e com outras perspectivas, no entanto, no caminho se depararam com questões atinentes ao campo de estudo. Os texto esbarraram no fato de que gênero "é um elemento constitutivo das relações sociais baseadas nas diferenças percebidas entre os sexos" e, por isso "é uma forma primária de dar significado às relações de poder" e "implica os símbolos culturalmente disponíveis que evocam representações simbólicas” (SCOTT, 1995, p. 86). Depararam-se com o fato do gênero (a raça e a classe também) estar no cerne da produção cultural, portanto. Nosso conselho é que abracem essa perspectiva, pois ela é capaz de iluminar e complexificar pesquisas que observam a produção das intrincadas relações entre mídia e consumo.

\section{REFERÊNCIAS}

BARDIN, Laurence. Análise de Conteúdo. São Paulo: Edições 70, 2011.

BOURDIEU, Pierre. As Regras da Arte. São Paulo: Companhia das Letras, 1996.

BOURDIEU, Pierre et al. El Ofício de Sociólogo. México: Siglo XXI, 1986.

LAGO, Cláudia; KAZAN, Evelyn; THAMANI, Manuela. Jornalismo e estudos de gênero: e a interseccionalidade, onde está? In: AGUIAR, Leonel; SILVA, Marcos Paulo da; MARTINEZ, Monica (org.) Desigualdades, Relações de Gênero e Estudos de Jornalismo. São Paulo: Intercom, 2018. Disponivel em: https://drive.google.com/file/d/1m4icSBgkmvwTIklgpOPSOMkt4gRxObx8/view. Acesso em: 22 set. 2020.

LAGO, Cláudia. Pierre Bourdieu e algumas lições para o Campo da Comunicação. Intexto,

7. O olhar para as masculinidades aparece em Sobre infância, saúde e gênero: discursos biomédicos na mídia impressa de 1990, que traz, nas referências bibliográficas, textos que discutem masculinidades, mas não explora no corpo do artigo e a palavra masculinidade aparece em Telenovelas brasileiras, mulheres da classe dominante e a moderna tradição de gênero, em meio a uma citação. 
Porto Alegre, n. 34, p. 728-722, set./dez. 2015. Disponível em: https://seer.ufrgs.br/intexto/ article/view/58561. Acesso em: 22 set. 2020

LAURETIS, Teresa de. A tecnologia de gênero. In: HOLANDA, Heloisa Buarque de (org.). Tendências e impasses: o feminismo como crítica cultural. Rio de Janeiro: Rocco, 1994. p. 206-242.

MARTINEZ, Monica; LAGO, Cláudia; LAGO, Mara Coelho de Souza. Estudos de gênero na pesquisa em jornalismo no Brasil: uma tênue relação. Revista FAMECOS, Porto Alegre, v. 23, n. 2, 2016. DOI: https://doi.org/10.15448/1980-3729.2016.2.22464. Acesso em 22 set. 2020.

PEREIRA DE SÁ, Simone; PAULO, Rodolfo V. de. Strike a pose! A mediação do videoclipe "Vogue" em performances do Carnaval carioca. Comunicação Mídia e Consumo, São Paulo, v. 16, n. 46, p. 376-396, maio/ago. 2019. Disponível em: http://revistacmc.espm.br/index.php/ revistacmc/article/view/190. Acesso em: 22 set. 2020.

SCOTT, Joan. Gênero: uma categoria útil de análise histórica. Educação e Realidade, Porto Alegre, v. 20, n. 2, p. 71-99, 1995.

TOMAZETTI, Tainan Pauli; CORUJA, Paula. Relações de gênero nos estudos de recepção e consumo midiático: perspectivas de teses e dissertações em comunicação entre 2010 e 2015. Novos Olhares, São Paulo, v. 6, n. 1, 2017. DOl: http://dx.doi.org 10.11606/issn.2238-7714. no.2017.131734. Acesso em: 22 set. 2020.

TOMAZETTI, Tainan Pauli. Genealogias dissidentes: os estudos de gênero nas teses e dissertações em Comunicação do Brasil. Tese (Doutorado em Comunicação e Informação) Faculdade de Biblioteconomia e Comunicação, Universidade Federal do Rio Grande do Sul., Porto Alegre, 2019

TRINDADE, Eneus. Tendências sobre publicidade e consumo em revistas científicas da comunicação Qualis A2 entre 2006 e 2017: publicidade e consumos digitais em foco. Signos do Consumo, São Paulo, v. 11, n. 2, p. 114-125, jul./dez. 2019. Disponível em: https://www. revistas.usp.br/signosdoconsumo/article/view/159029. Acesso em: 22 set. 2020. 